\title{
Noncontact monitoring of fatigue crack growth using high frequency guided waves
}

\author{
B. Masserey and P. Fromme ${ }^{\mathrm{b}}$ \\ ${ }^{a}$ Department of Mechanical Engineering, University of Applied Sciences, Fribourg, Switzerland \\ ${ }^{b}$ Department of Mechanical Engineering, University College London, WC1E 7JE, UK
}

\begin{abstract}
The development of fatigue cracks at fastener holes due to stress concentration is a common problem in aircraft maintenance. This contribution investigates the use of high frequency guided waves for the non-contact monitoring of fatigue crack growth in tensile, aluminium specimens. High frequency guided ultrasonic waves have a good sensitivity for defect detection and can propagate along the structure, thus having the potential for the inspection of difficult to access parts by means of non-contact measurements. Experimentally the required guided wave modes are excited using standard wedge transducers and measured using a laser interferometer. The growth of fatigue cracks during cyclic loading was monitored optically and the resulting changes in the signal caused by crack growth are quantified. Full three-dimensional simulation of the scattering of the high frequency guided ultrasonic waves at the fastener hole and crack has been implemented using the Finite Difference (FD) method. The comparison of the results shows a good agreement of the measured and predicted scattered field of the guided wave at quarter-elliptical and through-thickness fatigue cracks. The measurements show a good sensitivity for the early detection of fatigue damage and for the monitoring of fatigue crack growth at a fastener hole. The sensitivity and repeatability are ascertained, and the robustness of the methodology for practical in-situ ultrasonic monitoring of fatigue crack growth is discussed.
\end{abstract}

Keywords: Noncontact Measurement, High Frequency Guided Waves, Laser Interferometer, Fatigue Crack

\section{INTRODUCTION}

The development of fatigue cracks at fastener holes presents a common maintenance problem for aircraft, necessitating structural health monitoring [1]. As a safety requirement these must be detected before they have reached a critical length [2]. Ultrasonic bulk waves possess the necessary sensitivity for the detection and sizing of cracks [3], and sensors can be integrated [4]. An ultrasonic-based structural health monitoring method has been developed for the real time, insitu monitoring of fatigue cracks at fastener holes using an angle beam through transmission technique [5]. However, bulk wave ultrasonic testing necessitates local contact measurements on the damaged area of the inspected structure [6]. Guided ultrasonic waves allow for the monitoring of hard to inspect areas of large structures with limited access [7, 8, 9, 10], and have been successfully employed to monitor fatigue crack growth $[1,11]$. The potential of guided waves for noncontact measurement using a laser vibrometer has been demonstrated for fatigue crack detection in metallic structures $[12,13]$. Both the excitation and measurement of guided ultrasonic waves can be performed using noncontact laser technology [14]. However, the wavelength of the employed guided waves is usually significantly larger than in bulk wave testing, limiting the sensitivity for the detection of small defects $[15,16]$. Surface acoustic waves have been used for enhanced fatigue crack monitoring [17]. Guided ultrasonic waves in the higher frequency-thickness range have been investigated for defect detection over medium long distances [18, 19], allowing good sensitivity for the detection of small surface defects $[20,21]$. In this contribution fatigue crack growth monitoring has been performed using noncontact laser interferometry of high frequency guided waves. Full 3D Finite Difference (FD) simulations of the scattering of the high frequency guided wave modes has shown that the scattering at the crack leads to an amplitude reduction in the area behind the crack [22]. The laser measurement was thus performed with high precision in the shadow area behind the expected fatigue crack location [23]. The changes in the signal resulting from the fatigue crack growth were quantified on the basis of the variation of the energy of the high frequency guided ultrasonic wave pulse.

Sensors and Smart Structures Technologies for Civil, Mechanical, and Aerospace Systems 2014,

edited by Jerome P. Lynch, Kon-Well Wang, Hoon Sohn, Proc. of SPIE Vol. 9061, 90611D

(C) 2014 SPIE · CCC code: $0277-786 X / 14 / \$ 18 \cdot$ doi: 10.1117/12.2046312

Proc. of SPIE Vol. 9061 90611D-1 


\section{HIGH FREQUENCY GUIDED ULTRASONIC WAVE PROPAGATION}

Working in the frequency region where their wavelength is approximately half of the plate thickness (around $6.75 \mathrm{MHz}$ $\mathrm{mm}$ in aluminum) the first anti-symmetric and symmetric Lamb modes $A_{0}$ and $S_{0}$ have modeshapes with stress and displacement fields similar to a Rayleigh wave on each plate surface. As the first anti-symmetric and symmetric Lamb modes propagate with slightly different phase velocities, they continually shift in relative phase during propagation, causing the transfer of the energy between plate sides over a distance called the beatlength [24] or beating wavelength [25]. The beatlength $\mathrm{L}$ is calculated as

$$
L=\frac{2 \pi}{k_{A 0}-k_{S 0}}
$$

where $\mathrm{k}_{\mathrm{A} 0}$ and $\mathrm{k}_{\mathrm{S} 0}$ are the wave numbers of the first anti-symmetric and symmetric Lamb modes. The beatlength depends on the difference between the wave numbers $\mathrm{k}_{\mathrm{A} 0}$ and $\mathrm{k}_{\mathrm{S} 0}$ in the denominator term. With increasing frequency the difference between wave numbers decreases and thus the beatlength increases. For large frequency-thickness products the wave numbers of $\mathrm{A}_{0}$ and $\mathrm{S}_{0}$ converge to the wave number of a Rayleigh wave and the beatlength tends toward infinity, corresponding to the propagation of a Rayleigh wave at the surface of a semi-infinite medium. The Rayleighlike anti-symmetric and symmetric Lamb modes $\mathrm{A}_{0}$ and $\mathrm{S}_{0}$ are easily generated selectively above the cutoff frequencies of the higher Lamb wave modes using standard Rayleigh wave angle beam transducers [20]. The associated beating phenomenon can be used for the detection of small cracks on both plate sides or, selecting appropriate excitation frequency and position, for the inspection of structures where access is restricted by regularly spaced features such as stiffeners or stringers [21].

\section{EXPERIMENTS}

The fatigue crack growth monitoring was performed using four tensile specimens $3 \mathrm{~mm}$ thick, $70 \mathrm{~mm}$ wide and $600 \mathrm{~mm}$ long, made of aluminum alloy 2014 T6. A 1/4 inch diameter hole was drilled on the center line $200 \mathrm{~mm}$ from the end (Fig. 1a). The specimen was subjected to cyclic tensile loading in a servo-hydraulic testing machine (Fig. 1b). A maximum load of $26 \mathrm{kN}$ was selected so that the maximum stress in the vicinity of the hole is about $95 \%$ of the yield strength, in order to remain in the range of elastic deformation. The corresponding maximum nominal stress was approximately $124 \mathrm{MPa}$. The cyclic loading was performed with a stress ratio $R=0.1$ and a cycling frequency of $10 \mathrm{~Hz}$. The loading axis was parallel to the center line of the specimen. The crack initiation is expected to occur at the hole boundary at an angle of approximately $90^{\circ}$ relative to the loading axis. A small triangular starter notch, approximately $0.2 \mathrm{~mm}$ long, was made on one side of the specimen at the hole corner in order to prescribe the position where the crack would start growing. During fatigue testing the crack grew quarter-elliptically from the starter notch position to a length (and depth) of about $3 \mathrm{~mm}$. At that depth, corresponding to the specimen thickness, the crack quickly developed into a through-thickness crack. A standard Rayleigh wave angle beam transducer and wedge with a center frequency of $2.25 \mathrm{MHz}$ (Rayleigh wavelength $\lambda_{\mathrm{R}}=1.3 \mathrm{~mm}$ ) was clamped at a distance $d=125 \mathrm{~mm}$ from the hole center on the specimen surface opposite to the side where the starter notch was made. The distance, corresponding to half a beatlength at center frequency, was selected so that the energy is mainly concentrated on the notched specimen side when reaching the hole. The transducer was positioned in such a way that the main propagation line crossed the center of the hole, as displayed in Figure 1a. The specimen was wide enough so that the sides did not significantly affect the propagation of the incident wave field. The transducer was driven using a standard ultrasonic pulser-receiver. The frequency content of the generated ultrasonic pulse was wide band up to about 3.5 MHz. A noncontact heterodyne laser interferometer was used to measure the out-of-plane displacement component at a spot approximately $1 \mathrm{~mm}$ sideways from the hole and $1 \mathrm{~mm}$ behind the expected fatigue crack location on the same side of the plate as the starter notch. At this measurement location the energy of the wave pulse that propagates past the fatigue crack is expected to be highly affected by the crack growth. The laser demodulator output was bandpass filtered $(1 \mathrm{MHz}-5 \mathrm{MHz})$ around the center frequency and averaged (100 averages). The noncontact measurement allows for a very sensitive measurement with high spatial resolution (measurement spot diameter less than $0.1 \mathrm{~mm}$ ) of the influence of the fatigue crack on the propagating high frequency guided wave pulse. The measurement was repeated every 1'000 cycles, holding the specimen under maximum tensile load to avoid crack closure. The crack size was measured optically on the front surface (crack length) and through the hole thickness (crack depth) by means of an optical microscope. 


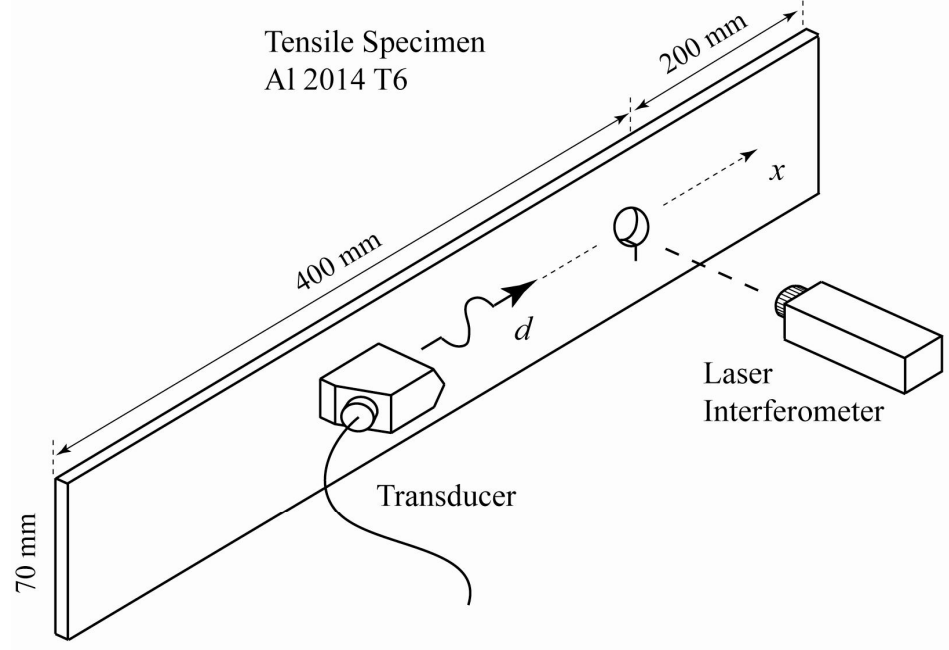

(a)

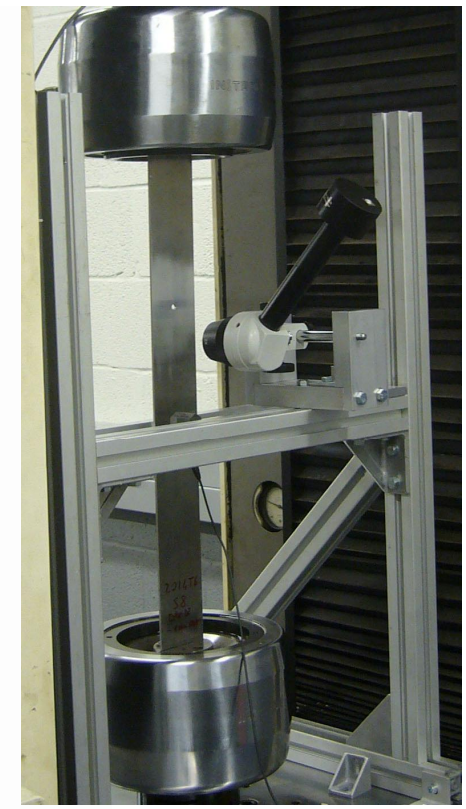

(b)

Fig. 1. Experimental setup: (a) tensile specimen with high frequency guided wave excitation and noncontact laser interferometer measurement; $(b)$ cyclic tensile loading setup with optical microscope.

\section{FINITE-DIFFERENCE SCATTERING SIMULATION}

A full three-dimensional Finite Difference (FD) code was used to simulate the scattering of the high frequency guided ultrasonic wave modes at the hole and the crack. The geometry was discretized on a Cartesian, staggered grid [26] using cubic elements with a side length of $50 \mu \mathrm{m}$ (approximately 20 nodes per Rayleigh wavelength). The hole geometry was approximated with the right-angled Cartesian grid, the grid size being small compared to the $6.35 \mathrm{~mm}$ diameter hole. The fatigue crack was implemented at the edge of the hole at an angle of $90^{\circ}$ relative to the main propagation axis. For crack sizes smaller than the plate thickness of $3 \mathrm{~mm}$, the crack contour was quarter-circular with point of origin at the hole corner. A through thickness crack with constant length starting from the hole edge was implemented for crack sizes above the plate thickness. The stress-free boundary conditions at the specimen and hole boundaries as well as in the crack were implemented as described in [27]. To reduce the computational effort, the $600 \mathrm{~mm}$ x $70 \mathrm{~mm}$ specimen was reduced to a $50 \mathrm{~mm} \times 70 \mathrm{~mm}$ aluminum plate. The simulation was performed separately for $\mathrm{A}_{0}$ and $\mathrm{S}_{0}$ Lamb modes using a 5 cycle sinusoid in a Hanning window with a center frequency of $2.25 \mathrm{MHz}$ as the excitation signal. The incident wave was generated $10 \mathrm{~mm}$ from the hole center by imposing the displacement field for the $\mathrm{A}_{0}$ or $\mathrm{S}_{0}$ mode in the two initial simulation steps as described in [28]. The simulation was repeated for crack sizes from $0 \mathrm{~mm}$ to $4 \mathrm{~mm}$ with a step size of $0.5 \mathrm{~mm}$. The out-of-plane displacement component was recorded on the specimen surface where the crack initiated for all grid points in a square area of $2 \mathrm{~mm} \times 2 \mathrm{~mm}$ with center point corresponding to the laser spot (1 mm sideways from hole and $1 \mathrm{~mm}$ behind the fatigue crack location). To be consistent with the measurements, the evaluation of the corresponding time signals as a function of the crack size was done on the basis of the combined results from the $\mathrm{A}_{0}$ and $\mathrm{S}_{0}$ simulations. As the five cycle tone burst used as excitation signal has a bandwidth $\Delta \mathrm{f}=1.8 \mathrm{MHz}$ (width of the main lobe), the dispersive behavior of the first Lamb modes was considered in the reconstitution of the time signal. Fast Fourier Transform (FFT) was applied to the out-of-plane displacement signals recorded for the $\mathrm{A}_{0}$ and $\mathrm{S}_{0}$ simulations. The resulting complex, discrete frequency spectra were subsequently phase shifted to take into account the additional propagation distance of $115 \mathrm{~mm}$. The phase shift was calculated for every frequency of the discrete spectra as the product of this distance with the wave number of the corresponding mode at that frequency. The resulting frequency spectra for the first anti-symmetric and the first symmetric Lamb mode simulations were added together and transformed back into the time domain by means of inverse FFT. Neglecting the influence of the beam spread, the resulting time series corresponds to the experimental configuration with the out-of-plane displacement component measured behind the crack for a Rayleigh-like wave generated at $125 \mathrm{~mm}$ from the hole center on the specimen surface opposite to the side where the crack initiated. 


\section{FRACTURE MECHANICS PREDICTION OF CRACK GROWTH}

The fatigue crack growth was predicted by means of a simple analytical model, assuming Forman law [29]. This model can be used to describe stable and unstable propagation for cracks when the plastic zone ahead of the crack tip is large compared to the mean grain size. The mathematical relationship describing Forman law is

$$
\frac{d a}{d N}=\frac{C_{1} \cdot \Delta K^{m_{1}}}{(1-R) K_{C}-\Delta K}
$$

where the crack growth rate $d a / d N$ is given as a function of the stress intensity factor range $\Delta K$, the stress ratio $R$, the material fracture toughness $K_{C}$ and two material parameters $m_{1}$ and $C_{1}$. For cyclic loading, the stress intensity factor range is defined as the difference between maximum and minimum stress intensity factors $K_{\max }$ and $K_{\min }$, computed as

$$
K_{\max / \min }=F \cdot \sigma_{\max / \min } \sqrt{\frac{\pi \cdot a}{Q}},
$$

where $\sigma$ is the nominal stress, $a$ is the crack depth, $Q$ is the shape factor for an ellipse and $F$ is a factor depending on crack depth, crack length, plate thickness, plate width and hole radius [30]. The stress intensity factors for crack depth and crack length are different, even though each of them depends on both axes of the quarter-elliptical defect. The stress intensity factor equations proposed in [30] are valid for a ratio of crack depth to crack length between 0.2 and 2; all other geometrical parameters were within the valid range. Crack growth prediction has been performed incrementally on the basis of Equation (2). A convergence analysis was performed to ensure that the selected cycle increment $\Delta N$ is small enough to obtain an accurate solution. A typical fatigue rate figure representing the measured crack growth rate $d a / d N$ as a function of the stress intensity factor range $\Delta K$ was used to determine the material parameters required for Forman propagation law. Initial parameter values for Al $2014 \mathrm{~T} 6$ were taken from [31] and varied within the typical range for aluminum until good agreement was found.

The number of cycles for which crack initiation occurred varied for the four investigated specimens, but due to the identical loading conditions the fatigue crack growth was repeatable between the specimens. To account for this and allow for a comparison between the 4 specimens, crack growth is shown as a function of the number of cycles before the crack was observed to have grown through the thickness of the specimen, which, unlike crack initiation, could be found exactly (accuracy of 1'000 cycles). The optically observed crack lengths and crack depths are shown for the four specimens in Figure 2. Despite an initially larger notch length on the specimen surface, the crack growth through the hole thickness is faster and leads to a through thickness defect before a crack length of $3 \mathrm{~mm}$ can be observed on the specimen surface.
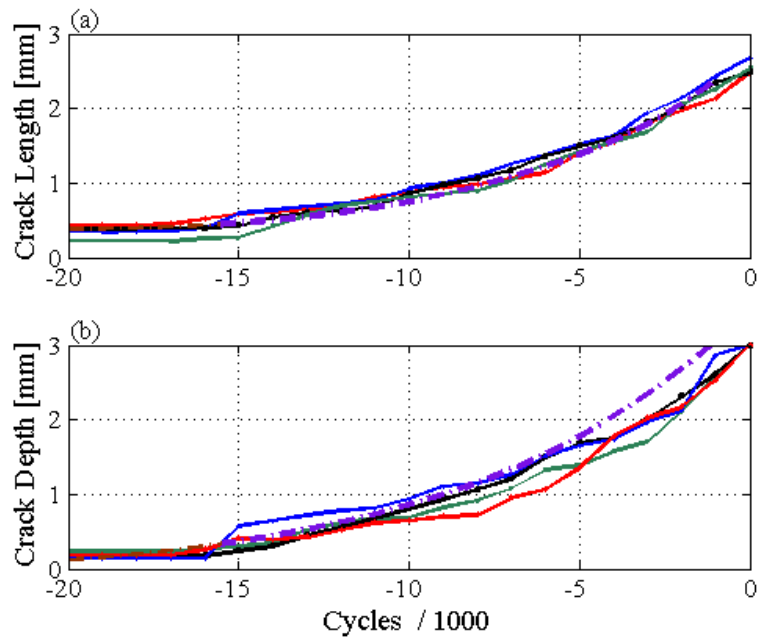

Fig. 2. Optically measured fatigue crack growth for 4 specimens (solid lines) and predicted fatigue crack growth (dashdotted): (a) crack length on specimen surface; (b) crack depth in fastener hole interior; plotted against number of cycles before crack grown through thickness. 

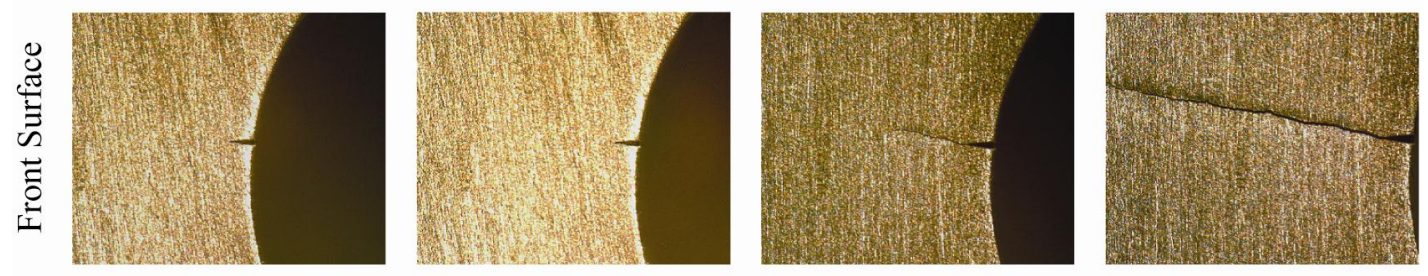

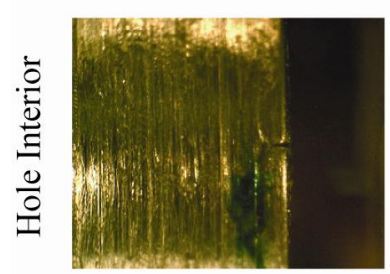

40 '000 cycles

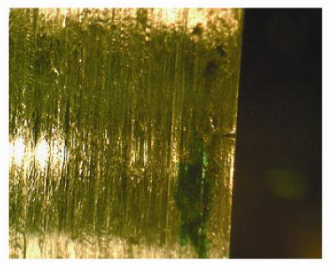

50 '000 cycles

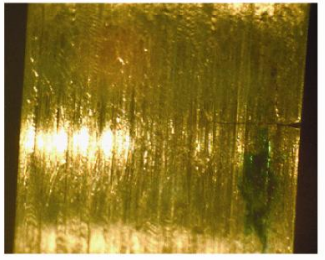

60’000 cycles

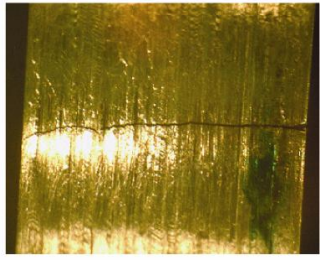

70 ’000 cycles

Fig. 3. Photographs for one specimen of starter notch and fatigue crack growth on front surface (top) and in hole interior (bottom).

Shown in Figure 3 are photographs taken using an optical microscope on the surface and through the hole thickness of one specimen when the fatigue crack initiation and growth occurred. For this specimen, the fatigue crack was first observed optically at $52^{\prime} 000$ cycles (16'000 cycles before a through thickness crack was observed) as a quarter-elliptical crack with a length of $0.39 \mathrm{~mm}$ on the front surface. Only the starter notch $(0.26 \mathrm{~mm} \times 0.17 \mathrm{~mm})$ is visible in the pictures for $40^{\prime} 000$ and $50^{\prime} 000$ cycles $\left(28^{\prime} 000\right.$ cycles and $18^{\prime} 000$ cycles respectively, before a through thickness crack was observed), while in the pictures for $60^{\prime} 000$ cycles $\left(8^{\prime} 000\right.$ cycles before a through thickness crack was observed) the quarter-elliptical crack can be seen with a length of $1.05 \mathrm{~mm}$ on the front surface and a depth of $1.06 \mathrm{~mm}$ through the thickness. The crack had grown through the thickness of the specimen at $68^{\prime} 000$ cycles (length on front surface: $2.48 \mathrm{~mm}$ ) and then continued to grow as a through crack with similar lengths on the front and back surfaces. The through thickness crack is shown at 70'000 cycles with a length on the front surface of $3.13 \mathrm{~mm}$.

The crack growth calculation for crack length and crack depth is shown in Figure 2 (dash-dotted line). For each specimen, the number of cycles when the crack was first observed optically both on the specimen surface and in the hole thickness was taken as reference to define the initial crack length and depth. The resulting crack sizes for all specimens were averaged to obtain initial values of $0.34 \mathrm{~mm}$ for crack depth and $0.45 \mathrm{~mm}$ for crack length. As the fatigue crack growth was comparable between the four specimens, a value of $15^{\prime} 500$ was taken as the average number of cycles before a through thickness crack was observed (observed range: 15'000 - 17'000 cycles).

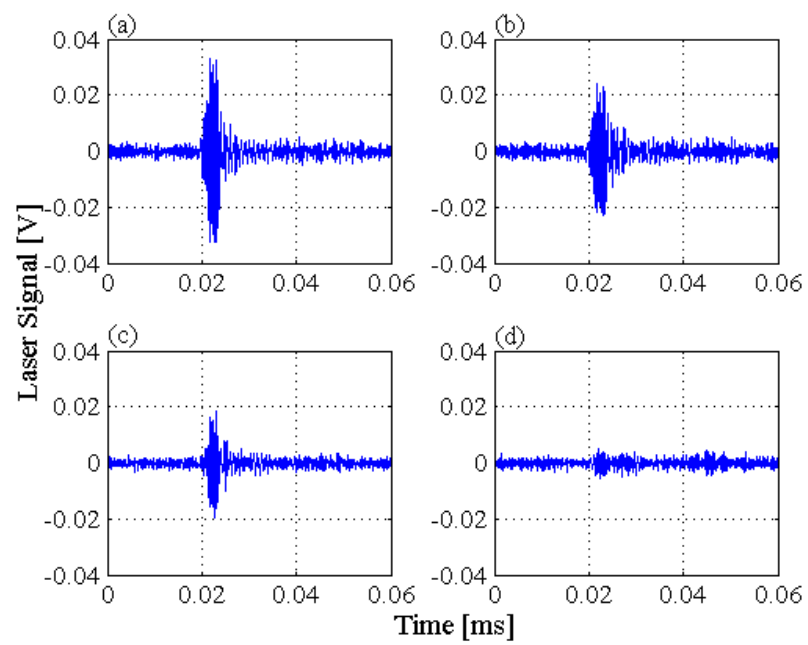

Fig. 4. Time traces of high frequency guided ultrasonic wave pulse measured on same specimen as in Figure 3 with laser interferometer at location behind fatigue crack close to hole; $f_{0}=2.25 \mathrm{MHz}, d=125 \mathrm{~mm}$ : a) $40^{\prime} 000$ cycles, b) 50’000 cycles, c) 60’000 cycles, d) 70’000 cycles. 
Based on this data, the fatigue crack growth was computed until the quarter-elliptical crack had grown through the specimen thickness. The resulting curves show excellent agreement for crack depth and good agreement for crack length. Similar to the measured crack growth, the predicted crack growth rate is more pronounced for the crack depth in the hole thickness, becoming larger than the crack length $12^{\prime} 500$ cycles before a through thickness crack is observed. Starting from the same initial values, a backward crack growth calculation was performed to estimate the defect size before the crack was observed optically. The calculation was stopped $21^{\prime} 000$ cycles before a through thickness crack was observed, as the criterion based on the ratio between crack length and crack depth was not satisfied anymore and, thus, the crack geometry was out of the valid range for stress intensity factor calculations. Based on the available backward prediction, an estimation of the crack size 20'000 cycles before a through thickness crack (and 3'000 - 4'000 cycles before a crack was observed optically) yields a crack length of $0.38 \mathrm{~mm}$, a crack depth of $0.09 \mathrm{~mm}$ and a corresponding quarterelliptical crack area of less than $0.05 \mathrm{~mm}^{2}$.

\section{NONCONTACT LASER MEASUREMENT FOR IMPROVED DETECTION SENSITIVITY}

The measured high frequency guided wave pulses behind the fatigue crack location are shown in Figure 4 for the same specimen and the same number of cycles as the photographs in Figure 3. The signal measured using the noncontact laser interferometer showed some variations and noise, partially due to a not perfect reflection of the laser beam from the specimen surface. Another potential source would be a movement of the measurement spot relative to the hole as the specimen moved or expanded (due to heat) in the clamps of the testing machine, while the laser interferometer was fixed to an external positioning system. The maximum amplitude of the ultrasonic pulse measured with the laser interferometer showed small variations of up to 5\% until 40'000 cycles (Figure 4a, 28'000 cycles before through thickness crack). A significant reduction of the pulse amplitude can be seen in Figure $4 \mathrm{~b}$ at $50^{\prime} 000$ cycles (18'000 cycles before through thickness crack), when no crack was observed optically. The decrease in pulse amplitude and energy continues for a part-through crack as can be seen for the pulse at $60^{\prime} 000$ cycles $\left(8^{\prime} 000\right.$ cycles before through thickness crack) in Figure 4c. When the crack has grown through the thickness almost no guided ultrasonic wave pulse can be measured any more directly behind the fatigue crack (Figure $4 \mathrm{~d}, 70^{\prime} 000$ cycles). In principle the drop in amplitude of the measured pulse is the expected behavior, as the non-contact monitoring location is behind the crack location from the excitation point and the growing fatigue crack blocks the path of the ultrasonic wave, leading to a shadow area behind the crack.

In order to quantify this, the changes in the guided wave pulse were evaluated for each measurement (every 1'000 cycles), for the fatigue experiments on the four specimens, using 3 different methods; extracting the maximum amplitude of the pulse, an energy-based parameter of the pulse and the amplitude of the frequency spectrum at $2.25 \mathrm{MHz}$ using FFT. The pulse was time-gated $(0.02 \mathrm{~ms}$ to $0.025 \mathrm{~ms}$ in Figure 4$)$ to reduce the influence of noise on the measurement for the energy and FFT calculations. The maximum amplitude was extracted for each of the time traces. This parameter showed some short term fluctuation between individual measurements within a range of up to $5 \%$ until -40 '000 cycles (40'000 cycles before through thickness crack) and 8\% until -30'000 cycles. The energy of the pulse was calculated according to Equation 4

$$
E_{n}=\int_{t_{1}}^{t_{2}}\left(x_{n}(t)\right)^{2} d t
$$

where $t$ is time and $x_{\mathrm{n}}(t)$ is the pulse at fatigue cycle $n$. The energy ratio $R_{L}$ was obtained by normalizing the energy parameter $E_{n}$ with the baseline energy parameter $E_{0}$

$$
R_{L}=\frac{E_{n}}{E_{0}},
$$

with

$$
E_{0}=\int_{t_{1}}^{t_{2}}\left(x_{0}(t)\right)^{2} d t
$$


where $x_{0}(t)$ is the baseline signal (averaged from the first 10 measurements). Calculating the energy parameter instead of taking the peak amplitude was found to be less sensitive to noise in the signal and to more accurately represent the signal, e.g., between Figures $4 \mathrm{~b}$ and $4 \mathrm{c}$ the significant drop in the pulse energy can be well quantified whereas only a small drop in maximum amplitude can be observed. The energy parameter showed short term fluctuation between consecutive measurements with a variation of up to 7\% until -40 '000 cycles and $15 \%$ until -30 ' 000 cycles. Furthermore the amplitude of the pulse at the center frequency of $2.25 \mathrm{MHz}$ was extracted using FFT. This showed a variation of up to $5 \%$ until $-40^{\prime} 000$ cycles and $11 \%$ until $-30^{\prime} 000$ cycles, and overall gave very similar results to the energy calculation. The increased variation after $-40^{\prime} 000$ cycles was due to the measurements for one specimen, with a drop in both energy and amplitude of the frequency spectrum. The reasons for this drop could not be related to any measurement variations or optically observed crack growth.

The energy ratios of the pulse measured with the noncontact laser interferometer for the 4 tensile specimens are shown in Figure 5a. The energy ratio and the approximate optically measured crack area (Figure $5 \mathrm{~b}$ ) are shown against the number of cycles before the crack grew through the plate thickness as detailed above to account for variations in the crack initiation. In Figure $5 \mathrm{~b}$ it can be seen that the crack growth was repeatable between the 4 specimens, with the crack optically visible $15^{\prime} 000-17^{\prime} 000$ cycles before a through thickness crack was observed. Evaluating the energy ratio of the signal from the start of the fatigue experiments until 30'000 cycles before a through thickness crack, a variation of the energy ratio of up to $15 \%$ can be observed, as described above. However, for all 4 specimens a significant drop in the ultrasonic pulse and thus energy ratio can be seen from about $25^{\prime} 000$ cycles before a through thickness crack occurred. $6^{\prime} 000$ cycles later (at $-19^{\prime} 000$ cycles) this drop was at least $30 \%$ for all specimens and therefore significantly larger than the maximum variation observed (twice as large). For none of the specimens the crack could be observed visually at this stage; the fatigue defect was only detected using the optical microscope 2'000 to 3'000 cycles later. From the averaged data of the smallest optically measured crack length for the 4 specimens a backward calculation was performed to estimate the crack size when the amplitude drop was observed in the guided ultrasonic wave signal. As mentioned in section 5, this predicted a maximum macroscopic crack area of less than $0.05 \mathrm{~mm}^{2}$ at this stage $\left(-20^{\prime} 000\right.$ cycles, $3^{\prime} 000-$ 4'000 cycles before a crack was observed optically). It appears that the employed measurement configuration with the local noncontact laser interferometer measurement of the guided wave pulse just past the expected crack location is very sensitive to detect small macroscopic cracks with good repeatability. It is assumed that additionally the microscopic damage around the macroscopic crack will have the effect of reducing the energy of the high frequency guided ultrasonic wave pulse.
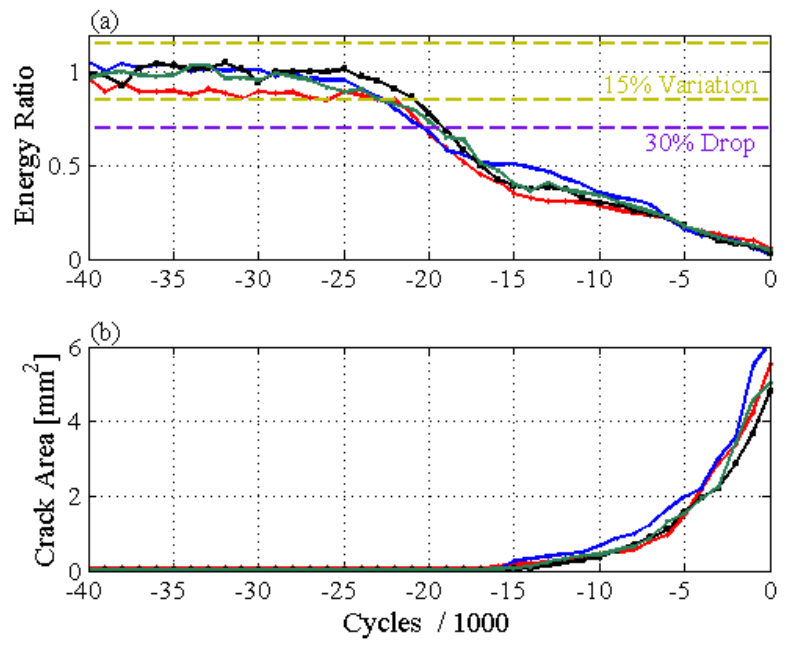

Fig. 5. (a) Energy ratio of high frequency guided ultrasonic wave pulse measured with laser interferometer at location behind fatigue crack close to hole for 4 specimens (solid lines); $15 \%$ energy variation and 30\% energy drop shown (dashed); (b) optically measured crack area for 4 specimens; plotted against number of cycles before crack grown through thickness. 


\section{COMPARISON OF MEASUREMENTS WITH FD PREDICTIONS FOR DEFECT SIZING}

The energy ratio drops to about 0.5 when the crack was first seen using the optical microscope and then drops close to zero when the crack has grown through the thickness of the specimen and blocks the path of the guided ultrasonic wave pulse. This phenomenon can be seen more clearly in Figure 6, where the energy for all 4 specimens was plotted against the optically visible crack area. This was observed consistently for the 4 tensile specimens, with some variation between the 4 specimens for small, part-thickness cracks (up to $2 \mathrm{~mm}^{2}$ ) and very good repeatability for larger fatigue cracks. The interesting observation was the significant drop in pulse amplitude and thus energy ratio before the crack had grown large enough to be observed optically. A 30\% drop in amplitude occurs around the number of cycles when an estimated macroscopic crack area of less than $0.05 \mathrm{~mm}^{2}$ was predicted from the crack growth model. This drop is twice as large as the maximum variation of the measurements without damage (15\%).

Using the FD model described earlier, the high frequency guided ultrasonic wave signal was predicted in the vicinity of the hole and crack. For the location of the noncontact laser interferometer measurement just behind the fatigue crack, the evaluated energy ratio against the crack area is shown in Figure 6 as the dash-dotted line. The predicted drop in ultrasonic signal due to the shadow effect of the crack can be observed. For small fatigue cracks (up to $2 \mathrm{~mm}^{2}$ ) the FD simulations predict a smaller energy drop than measured experimentally. It is expected that this is due to fatigue damage that has not been observed and modeled. Micro-structural damage typically occurs around the macroscopic fatigue crack. Combined with the small (less than $0.05 \mathrm{~mm}^{2}$ ) macroscopic fatigue crack predicted from the crack growth model (but not observed optically), this leads to the observed drop in ultrasonic pulse amplitude. This is consistent with the observed drop in the ultrasonic signal before the fatigue crack was detected using the optical microscope. This noncontact measurement close to the defect location gives an early indication of the fatigue crack before the crack is large enough to be observed optically with the employed microscope. From Figure 6 it can be seen that, for a crack area larger than $2 \mathrm{~mm}^{2}$, the predicted and measured energy ratios for the fatigue cracks correlate well, when plotted against the crack area. This allows in principle an approximate sizing of the fatigue damage for a known configuration.

From the FD simulations the influence of the geometric configuration and signal evaluation was investigated. The choice of the time window (in the absence of noise) has almost no influence on the energy drop for small (less than $2 \mathrm{~mm}^{2}$ ) cracks. For larger cracks the removal of the time window leads to a slightly larger predicted energy, as additional scattering phenomena lead to some energy arriving later in time than the direct ultrasonic wave pulse. The distance $d$ between the excitation location and fastener hole (damage location) was varied to investigate the influence of the beating effect and thus energy variation through the depth of the specimen. While some variation in the energy ratio curves was found, overall the curves show a similar dependency on the fatigue crack area. It was concluded that small inaccuracies in the positioning of the excitation wedge transducer will have a negligible influence on the observed results.

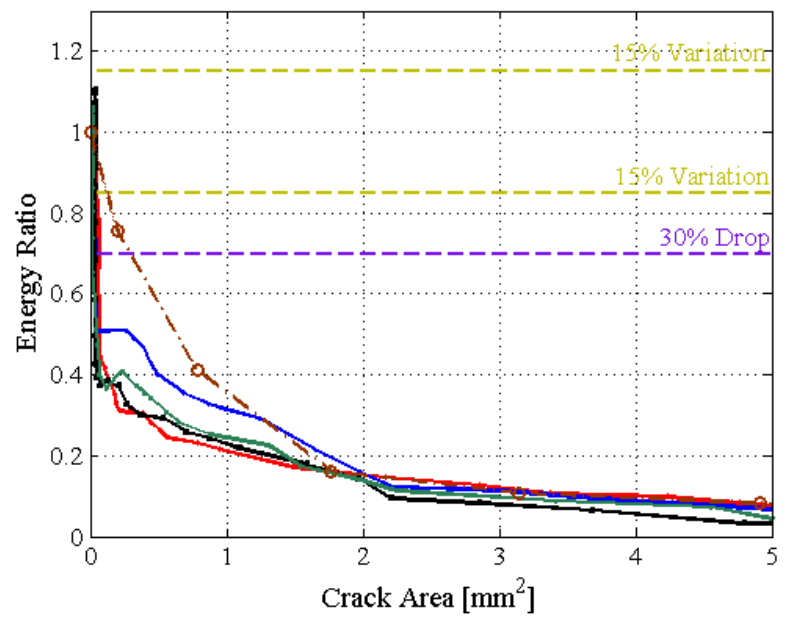

Fig. 6. Energy ratio of high frequency guided ultrasonic wave pulse measured with laser interferometer at location behind fatigue crack close to hole for 4 specimens (solid lines); 15\% energy variation and 30\% energy drop shown (dashed); FDM calculation (dash-dotted, circles); plotted against approximate optically measured crack area. 
Furthermore, the influence of the exact location of the laser measurement spot relative to the fastener hole and fatigue crack location was investigated for a variation of up to $2 \mathrm{~mm}$ in each direction. As long as the measurement spot remains in the shadow area of the fatigue crack (i.e., is behind the crack in the propagation direction of the guided wave pulse), only a small influence on the drop in the energy ratio was predicted. However, for a variation of the measurement location in the width direction of the specimen a significant influence on the pulse energy was predicted. Placing the measurement spot too far from the hole it would not be possible to detect small fatigue cracks (less than $2 \mathrm{~mm}^{2}$ ) as the energy drop is significant only above that crack size. This illustrates the necessity of high precision, local noncontact measurements for the early detection of fatigue damage before it can be observed optically.

\section{CONCLUSIONS}

The noncontact measurement of high frequency guided ultrasonic waves for fatigue crack growth monitoring at fastener holes has been studied. The propagation and scattering of the high frequency guided ultrasonic wave modes were simulated using the finite difference method. Experimentally, the guided ultrasonic wave pulse was measured in the shadow area behind the expected fatigue crack location using a laser interferometer, holding the specimen under tensile load. The changes in the ultrasonic signal were quantified on the basis of the energy ratio of the high frequency guided ultrasonic wave pulse to the undamaged case. The resulting energy drop due to the blocking of the guided ultrasonic wave propagation was repeatable between the four measured specimens. A significant drop of the energy of more than $30 \%$ had occurred before the crack had grown large enough for optical detection using a microscope. From fatigue crack growth calculations it was predicted that this corresponds to a macroscopic fatigue crack area of less than $0.05 \mathrm{~mm}^{2}$ (and the micro-structural damage around the macroscopic fatigue crack). This noncontact measurement close to the defect location therefore gives an early indication of fatigue damage. For small fatigue cracks the simulations predict a smaller energy drop than measured experimentally. This is consistent with the observed drop in the ultrasonic signal before the fatigue crack was detected using the optical microscope. For larger cracks the predicted and measured energy ratios correlate well with the optically measured crack area, showing the potential for crack sizing. Further measurements should investigate the relevance of the load on the early detection of fatigue cracks and the applicability of the methodology for the long-term monitoring of complex, multi-layered aerospace structures in real applications.

\section{FUNDING}

This work was partially supported by the Swiss National Science Foundation [grant number PBEZ2-114186], and the UK Engineering and Physical Sciences Research Council (EPSRC) [grant number EP/D065011/1].

\section{REFERENCES}

[1] Cho, H. and Lissenden, C. J., "Structural health monitoring of fatigue crack growth in plate structures with ultrasonic guided waves," Struct. Health Monit. 11, 393-404 (2012).

[2] Dalton, R. P., Cawley, P. and Lowe, M.J.S., "The potential of guided waves for monitoring large areas of metallic aircraft fuselage structures," J. Nondestr. Eval. 20, 29-46 (2001).

[3] Bövik, P. and Boström, A., "Model of ultrasonic nondestructive testing for internal and subsurface cracks," J. Acoust. Soc. Am. 102, 2723-2733 (1997).

[4] Rakow, A. and Chang, F.-K., "A structural health monitoring fastener for tracking fatigue crack growth in bolted metallic joints," Struct. Health Monit. 11, 253-267 (2012).

[5] Michaels, J. E., Michaels, T. E. and Mi, B., "An ultrasonic angle beam method for in situ sizing of fastener hole cracks," J. Nondestruct. Eval. 25, 3-16 (2006).

[6] Castaings, M., Le Clezio, E. and Hosten, B., "Modal decomposition method for modeling the interaction of Lamb waves with cracks," J. Acoust. Soc. Am. 112, 2567-2582 (2002).

[7] Fromme, P., Wilcox, P. D., Lowe, M. J. S. and Cawley, P., "On the development and testing of a guided ultrasonic wave array for structural integrity monitoring," IEEE Trans. Ultrason. Ferroelectr. Freq. Control 53, 777-785 (2006).

[8] Doherty, C. and Chiu, W. K., "Scattering of ultrasonic-guided waves for health monitoring of fuel weep holes," Struct. Health Monit. 11, 27-42 (2012).

[9] Fromme, P., "Monitoring of Plate Structures Using Guided Ultrasonic Waves," in Rev. Prog. QNDE 27, ed. by D.O. Thompson and D.E. Chimenti, AIP Conference Proceedings 975, New York, 78-85 (2008). 
[10] Fromme, P., "Health Monitoring of Plate Structures using Guided Waves," Proceedings of SPIE 6935, 69350W (2008).

[11] Fromme, P. and Sayir, M. B., "Detection of cracks at rivet holes using guided waves," Ultrasonics 40, 199-203 (2002).

[12] Leong, W.H., Staszewski, W.J., Lee, B.C., and Scarpa, F., "Structural health monitoring using scanning laser vibrometry: III. Lamb waves for fatigue crack detection," Smart Mater. Struct. 14(6), 1387-1395 (2005).

[13] Fromme, P. and Sayir, M. B., "Measurement of the scattering of a Lamb wave by a through hole in a plate," J. Acoust. Soc. Am. 111(3), 1165-1170 (2002).

[14] Sohn, H., Dutta, D., Yang, J.Y., Park, H. J., DeSimio, M., Olson, S., and Swenson, E., "Delamination detection in composites through guided wave field image processing," Compos. Sci. Technol. 71(9), 1250-1256 (2011).

[15] Alleyne, D. N. and Cawley, P., "The interaction of Lamb waves with defects," IEEE Trans. Ultrason. Ferroelectr. Freq. Control 39(3), 381-397 (1992).

[16] Fromme, P., Wilcox, P.D., Lowe, M., and Cawley, P., "On the Scattering and Mode Conversion of the A0 Lamb Wave Mode at Circular Defects in Plates," in Rev. Prog. QNDE, Vol. 23, ed. by D.O. Thompson and D.E. Chimenti, AIP Conference Proceedings 700, New York, 142-149 (2004).

[17] Connolly, G. D. and Rokhlin, S. I., "Enhancement of fatigue crack monitoring by surface acoustic wave reflection and modulation in a space-cycle-load domain: an imaging approach," Struct. Health Monit. 11(2), 187-196 (2012).

[18] Terrien, N., Osmont, D., Royer, D., Lepoutre, F., and Déom, A., "A combined finite element and modal decomposition method to study the interaction of Lamb modes with micro-defects," Ultrasonics 46(1), 47-78 (2007).

[19] Greve, D.W., Zheng, P., and Oppenheim, I.J., "The transition from Lamb waves to longitudinal waves in plates," Smart Mater. Struct. 17(3), 035029 (2008).

[20] Masserey, B. and Fromme, P., "On the reflection of coupled Rayleigh-like waves at surface defects in plates," J. Acoust. Soc. Am. 123(1), 88-98 (2008).

[21] Masserey, B. and Fromme, P., "Surface defect detection in stiffened plate structures using Rayleigh-like waves," NDT\&E Int. 42(6), 564-572 (2009).

[22] Masserey, B. and Fromme, P., "In-situ Monitoring of Fatigue Crack Growth at Fastener Holes Using Rayleigh-like Waves," in Rev. Prog. QNDE 27, ed. by D.O. Thompson and D.E. Chimenti, AIP Conference Proceedings 975, New York, 1484-1491 (2008).

[23] Masserey, B. and Fromme, P., "Fatigue Crack Growth Monitoring using High Frequency Guided Waves," Struct. Health Monit. 12, 484-493 (2013).

[24] Ti, B.W., O'Brien, W.D., and Harris, J.G., "Measurements of coupled Rayleigh wave propagation in an elastic plate," J. Acoust. Soc. Am. 102(3), 1528-1531 (1997).

[25] Auld, B. A., [Acoustic Fields and Waves in Solids] Wiley, New York, Vol. 2, 93-94 (1973).

[26] Madariaga, R., "Dynamics of an expanding circular fault," Bull. Seismol. Soc. Am. 66(3), 639-666 (1976).

[27] Masserey, B. and Mazza, E., "Analysis of the near-field ultrasonic scattering at a surface crack," J. Acoust. Soc. Am. 118(6), 3585-3594 (2005).

[28] Munasinghe, M. and Farnell, G. W., "Finite difference analysis of Rayleigh wave scattering at vertical discontinuities," J. Geophys. Res. 78(14), 2454-2466 (1973).

[29] Forman, R.G., "Study of fatigue crack initiation from flaws using fracture mechanics theory," Eng. Fract. Mech. 4(2), 333-345 (1972).

[30] Newman, J.C. and Raju I.S., "Stress-Intensity Factor Equations for Cracks in Three-Dimensional Finite Bodies," in Fracture Mechanics: Fourteenth Symposium - Volume I: Theory and Analysis, ed. by J.C. Lewis and G. Sines, Am. Soc. Test. Mater. STP 791, I-238-I-265 (1983).

[31] Berger, C., Blauel, J.G., Pyttel, B., and Varfolomeyev, I., "Fracture Mechanics Proof of Strength for Engineering Components", FKM Guideline $3^{\text {rd }}$ Ed. VDMA, Frankfurt (2005). 